\title{
Evaluation of Concrete Corrosion using EMI Sensor
}

\author{
Aneesh A. Chand \\ School of Engineering \& Physics \\ University of the South Pacific \\ Suva, Fiji \\ aneeshamitesh@gmail.com
}

\author{
Kushal A. Prasad \\ School of Engineering \& Physics \\ University of the South Pacific \\ Suva, Fiji \\ kushalaniketp@gmail.com
}

\author{
Kabir A. Mamun \\ School of Engineering \& Physics \\ University of the South Pacific \\ Suva, Fiji \\ kabir.mamun@usp.ac.fj
}

\author{
F. R. Islam \\ School of Science \& Engineering \\ University of Sunshine Coast \\ Queensland, Australia \\ fislam@usc.edu.au
}

\begin{abstract}
Reinforced Concrete (RC) is globally used to make the building structure strong and more durable. Civil and structural engineers face major challenges as concrete structures deteriorate and get weaker. Recent development in field of assessing and monitoring the health condition of the building structure have shown that corrosion in concrete reinforcement is the cause of failure. Thus, there lies a better research opportunity in the field of monitoring and assessing health condition of the building structure. This paper presents an innovative technique of initial monitoring of corrosion in concrete structures using NonDestruction Evaluation (NDE). An early monitoring sensor was developed using Faradays law of electromagnetic induction (EMI) principle, multiple loop coil (MLC) acts a sensor which has a receiver and transmitter coil. The placement of the two coils on concrete structures measures the potential difference which later is used to analyse the level of corrosion.
\end{abstract}

Keywords- electromagnetic induction, non-destructive evaluation, multiple-loop coil and reinforced concrete (RC)

\section{INTRODUCTION}

Reinforced Concrete (RC) is the most momentous and composite element in civil engineering and construction purposes which makes the building strong and more durable [1]. The current state-of-the-art gives an overview that corrosion of steel reinforcement is the main cause of deterioration and early failure of RC structures, this leads to enormous costs for inspection, maintenance, restoration and replacement of infrastructure $[2,3]$. However, concrete corrosion process takes decades to occur depending on the environmental condition.

According to literature [2, 3], several methods have been developed and used for evaluate the degree of corrosion in concrete structures mainly for coastal environment. Previously, destructive techniques were used to assess the condition, which has few disadvantage such as time consuming and money. However, to overcome the problem associated with destructive methods of testing the RC for corrosion many non-destructive evaluation techniques have evolved in recent years due to as technological advancement. Few method performed by different researcher are as follows: open circuit potential (OCP) monitoring is called as electrochemical methods [4], electromagnetic (EM) methods (i.e., ground penetrating radar (GPR)) [5], elastic wave methods (i.e., ultrasonic pulse velocity (UPV) [6], galvanostatic pulse method (GPM) [7], electrochemical noise (EN)) [8], resistivity method [9], polarization resistance [10], optical sensing methods (i.e., fiber Bragg grating (FBG)) [11], acoustic emission (AE) [12], impact echo (IE)) [13], infrared thermography (IRT) and most common methods used is visual inspection [14]. Whereas common methods used for monitoring in RC structures are visual inspection, polarization resistance, OCP, and other electrochemical methods. Interestingly, electromagnetic induction (EMI) is another techniques which could be used to monitoring and assessing RC structure $[3,15]$.

Recently, a NDE of corrosion in RC structure was developed using the Faraday's Law of EMI. The designed prototype works with a MLC sensor, which consists of primary and secondary search coils. The search coil acts like magnetic antenna which sends and receives AC signal pulse [3, 15].

This paper presents an experimental study on the EMI to evaluate corrosion processes in the rebar in concrete structures. The rest of this paper are organised as follows: In Section II corrosion process, Section III sensor design. Experimental test is presented in Section IV followed by results and discussion in Section V whereas Section VI concludes the paper.

\section{CORROSION PROCESS}

Corrosion in $\mathrm{RC}$ structure is an oxidation process that depends on the environment and geographic location it is exposed to such as rain, humidity, sea water and other chemicals $[2,3]$.

The life time of the concrete structure is depending on the level of corrosion present in a structure. Chloride ions and carbon dioxide are the main cause of corrosion; initially corrosion on $\mathrm{RC}$ is cracks on the surface, later the rate of corrosion increase significantly due to chloride ions and carbon dioxide entering through cracks [16].

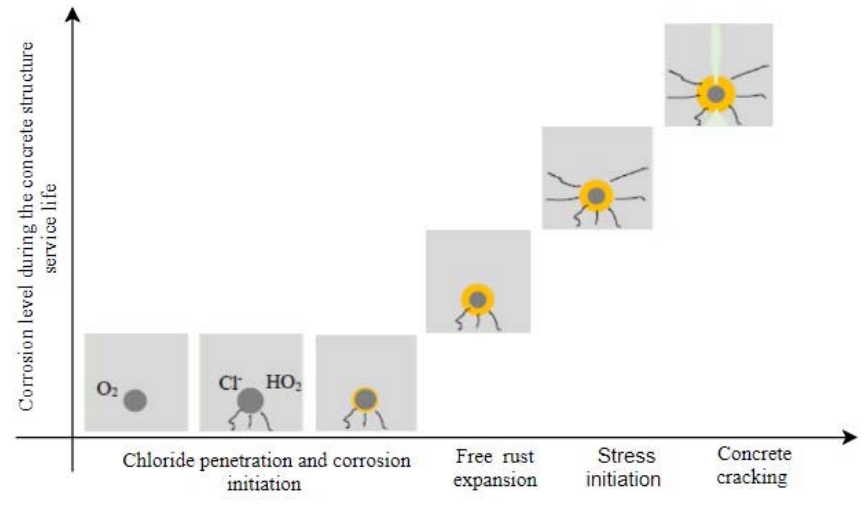

Fig. 1. Mineral prospecting using TDEM sounding method [6, 7].

In addition, rust layer expands instigating cracks or spalling in RC. Apart from these, there are few criteria which describes the stages of the chloride stimulated corrosion process and the resulting deterioration of concrete thus affecting and defining the service life of RC structures. These classification is useful to 
improve the NDE techniques according to the corrosion phase of the structure. It can be said that six phases of concrete corrosion process can be directed for NDE of the service life of concretes as shown in Fig. 1. However, the corrosion process determined using the oxidation process and iron dissolution proceeds according to (1).

$$
\mathrm{Fe} \rightarrow \mathrm{Fe}^{2}+2 e^{-}
$$

Water is used in construction and concrete industries, once the rebar's is exposed or come in contact to oxygen, during curing stage of concrete.

$$
2 \mathrm{H}_{2} \mathrm{O}+\mathrm{O}_{2}+4 e^{-} \rightarrow 4 \mathrm{OH}^{-}
$$

Water and oxygen are the main redox reactions in the corrosion process which is shown in (2). The anodic oxidation of iron and the cathode reduction of oxygen results in the production of $\mathrm{Fe}(\mathrm{OH})_{2}$ as given in (3). The product obtained in (3) is just one of the possible corrosion products, depending on the surrounding environment.

$$
2 \mathrm{Fe}^{2+}+2 \mathrm{OH} \rightarrow \mathrm{Fe}(\mathrm{OH})_{2}
$$

The summary of the all the reaction occurring during the corrosion process is abstracted in Fig. 2. Transfer of electrons is from anode to cathode through electronic current, according to (3) where oxygen reduction takes place, only cathode reaction is to be considered.

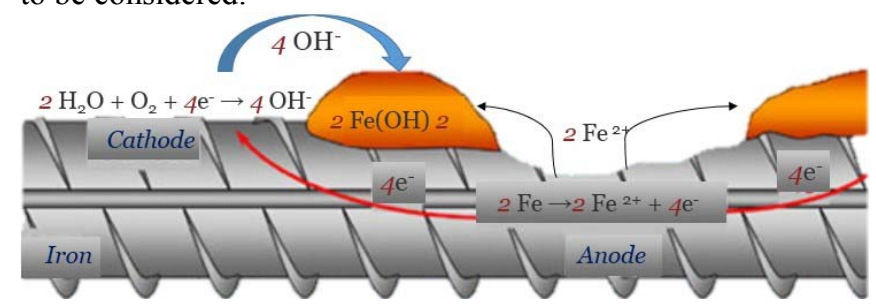

Fig. 2. Schematic representation of chloride induced pitting corrosion.

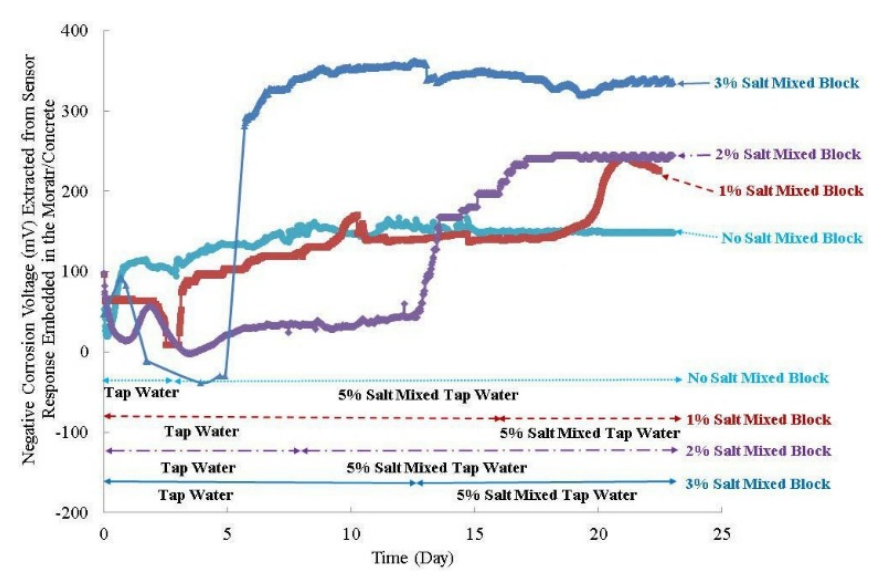

Fig. 3. Accelerated analysis of corrosion process [17].

An experiment was carried out to see the corrosion process with different percentage of salt in RC structure [17]. The test was conducted using no salt, and with $1 \%, 2 \%$, and $3 \%$ salt and the inspected data are shown in Fig. 3. The experimental results have clearly shown that how the chloride concentration in the concrete specimen affects the corrosion potential of steel reinforcement.

\section{SENSOR DESIGN}

The sensor developed in this work was using the Faradays law of EMI principle. The proposed sensor is designed with 24 $\mathrm{VAC}$ at frequency of $300 \mathrm{~Hz}$. A concentric MLC sensor was developed in this work, as it has added advantage of providing larger area of detection field and greatest detection depth [3, 15]. The outer (transmitter) and inner (receiver) coil has the diameters of $175 \mathrm{~mm}$ and $135 \mathrm{~mm}$ respectively as shown in Fig. 4 . The search coil was made using a 34 gauge copper winding wire.

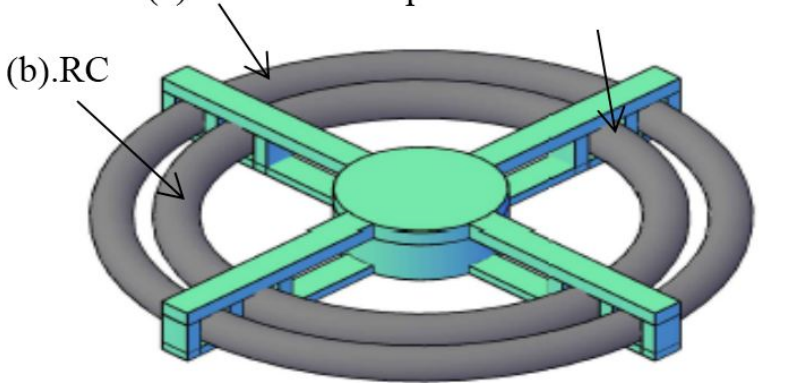

Fig. 4. MLC design for EMI Senor, (a) Transmitter Coil with 1000 turns and (b) Receiver Coil with 1500 turns.

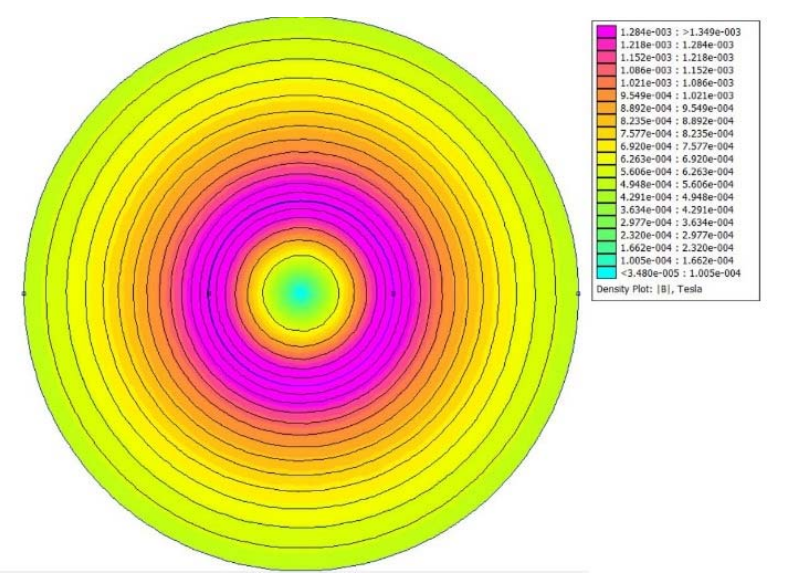

Fig. 5. Flux distribution for an EMI sensor in free space [3].

The sensor was simulated using a non-commercial FEMM software to examine the region of flux distribution by the transmitter search coil. The distribution of the electromagnetic field (EMF) in the region of interest is shown in Fig. 5 with the presence of a steel bar with $300 \mathrm{~Hz}$ of frequency.

\section{EXPERIMENT TEST}

The prototype specimen block was made using the mould as shown in Fig. 6. According to the manufacturers' instructions (local materials, sand, cement and builder mix, 1:2:1 respectively) concrete specimen were made and cured for 21 days. Three specimen was exposed to different type of 
environment i.e. block 1 normal room temperature $25^{\circ} \mathrm{C}$, block 2 distilled water and block 3 sea water with $35 \mathrm{~g} / \mathrm{kg}$ salinity for 13 weeks and tests were conducted during this period. The sensor was placed coplanarly on the surface for each sample and the obtained results is discussed under Section V.

(a)

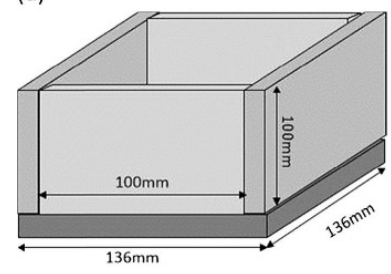

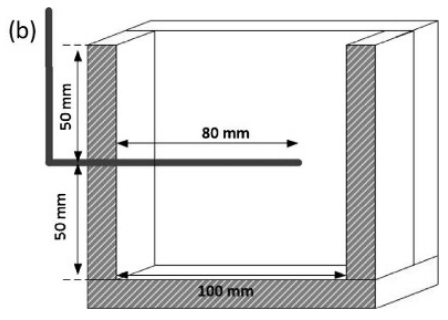

Fig. 6. Schematic of (a) mould box frame for specimen with inner dimension of $100 \mathrm{~mm} \times 100 \mathrm{~mm} \times 100 \mathrm{~mm}$ and (b) cross-section of the mould with rebar [18].

\section{RESUlTS AND DisCUSSION}

In this section, the inspected results obtained by EMI sensor, with $12 \mathrm{~mm}$ and $16 \mathrm{~mm}$ rods in the three different types of specimen which were exposed to diverse environments are analysed.

\section{A. Coplaner-placed Sensor}

A control and accelerated corrosion experiment was performed out on each specimen for 13 weeks and the potential for each was measured using an EMI sensor. After 21 days, it was put in sea water with $35 \mathrm{~g} / \mathrm{kg}$ salinity by weight with water solution. Initially, $4.4 \mathrm{~V}$ was on air and after that it was placed on each block, the end result of chloride concentration on the corrosion sensor response was more on sea water using coplanar placement as shown in Figs. 7 and 8. The observations were noticed while collecting the data for each concrete specimen are as follows: The response for the transmitted single differs with each type of concrete specimen. This implies that the strength of pulse received and the time taken for the pulse to be received is varied due to different level of corrosion. However, the different level of corrosion exhibits different behavior to the EM pulse sent through it. Measuring this difference can enable us to measure different level of corrosion but this will require a lot of experiment in order to give an appropriate level of corrosion as shown in Fig. 10.

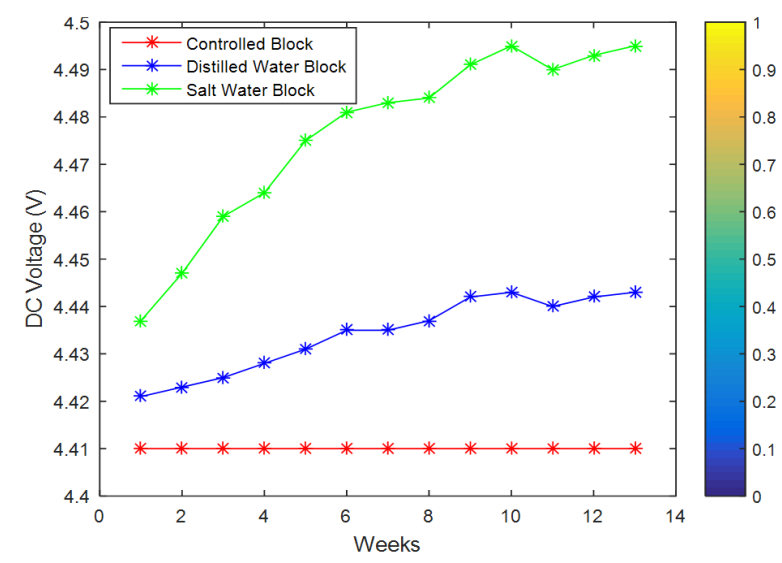

Fig. 7. EMI response for $12 \mathrm{~mm}$ rod for three different environments

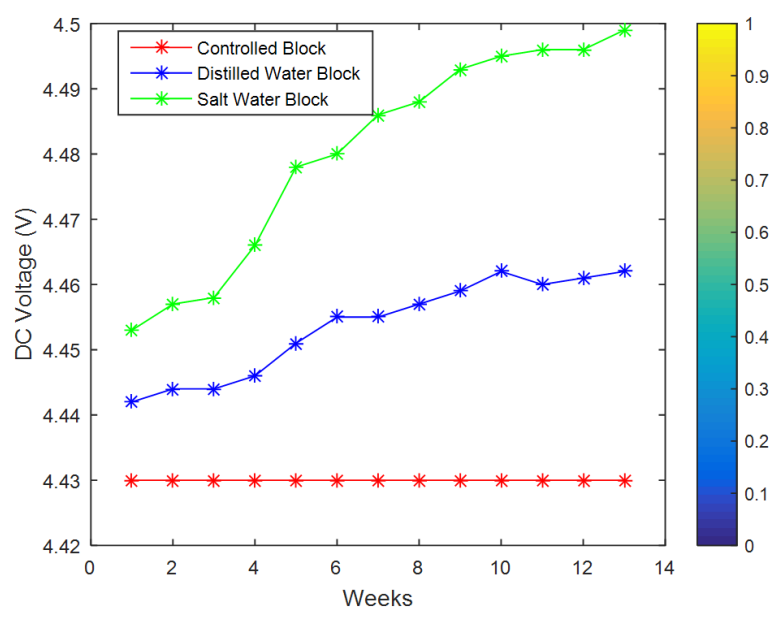

Fig. 8. EMI response for $16 \mathrm{~mm}$ rod for three different environments.

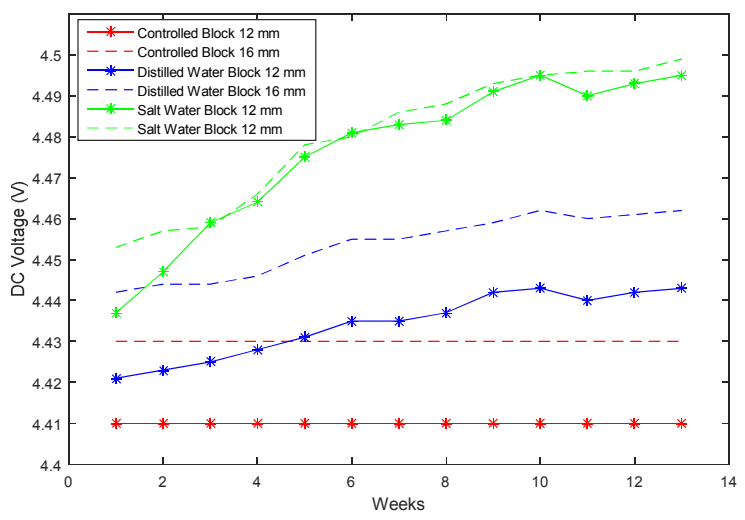

Fig. 9. Summary of $12 \mathrm{~mm}$ and $16 \mathrm{~mm}$ rod in different environment condition.

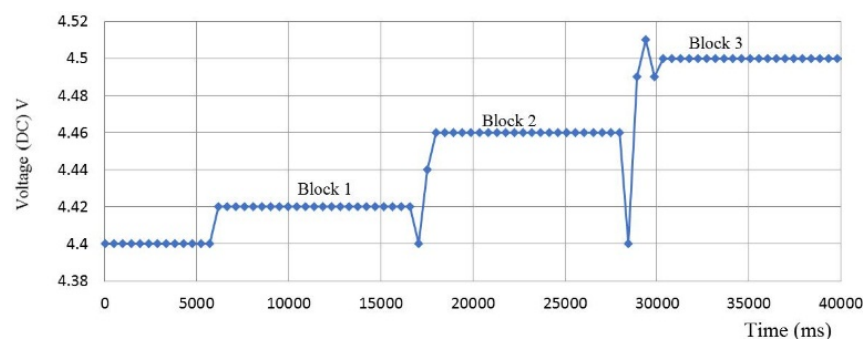

Fig. 10. Accelerated Corrosion Level of each Block after exposing to different Environments.

\section{CONCLUSION}

This research corroborated an NDE corrosion sensing EMI based sensor design and encapsulation of suitability for longterm installed monitoring. Faraday's Law of EMI was appropriate in designing the MLC which can generate signals and displaying the differences between a dry concrete block and those submerged in distilled water and a sea water solution.

The principle goal for this research was verified, that EMI sensor was able to distinguish between three blocks using potential different $(\mathrm{V})$ technique. Change in potentials indicate corrosion level in the concrete structures, the conductivity of the concrete also increases due to the changes in the chemical 
contents which cause changes to the electric field passed through the concrete. Measurement of this changed electromagnetic field enables to identify corrosion in concrete through EMI principle. However, further research is needed in this area along with different salts types, salt concentration, period of exposure to salts and the mortar ratio would further enhance the research methodology.

\section{ACKNOWLEDGMENT}

The authors would like to acknowledgment the University of The South Pacific and School of Engineering and Physics for funding this research project and research team for completion of this project.

\section{REFERENCES}

[1] I. Mansouri, M. Shariati, M. Safa, Z. Ibrahim, M. M. Tahir, and D Petković,"Analysis of influential factors for predicting the shear strength of a V-shaped angle shear connector in composite beams using an adaptive neuro-fuzzy technique," Journal of Intelligent Manufacturing vol.30, no. 3, pp.1247-1257, 2019.

[2] Yao, Li, Yin Shi-ping, and C. Wen-jie,"Seismic behavior of corrosiondamaged RC columns strengthened with TRC under a chloride environment," Construction and Building Materials. vol. 201, pp.736745, 2019.

[3] K. A. Mamun, R. N. Deo, F. R Islam, H. R. Pota, A. A. Chand, K. A. Prasad, A. Cakacaka," A Prototype of an Electromagnetic Induction Sensor for Non-Destructive Estimation of the Presence of Corrosive Chemicals Ensuing Concrete Corrosion," Sensors. vol.19, no. 1, pp.1-12, 2019.

[4] H. W. Song and V. Saraswathy, "Corrosion monitoring of reinforced concrete structures-A," Int. J. Electrochem. Sci. vol. 2, pp.1-28, 2007.

[5] X. Dérobert, J. Iaquinta, G. Klysz, and Jean-Paul Balayssac, "Use of capacitive and GPR techniques for the non-destructive evaluation of cover concrete," NDT \& E International. vol. 41, no. 1, pp.44-52, 2008.

[6] M. T. Liang and J. Wu, "Theoretical elucidation on the empirical formulae for the ultrasonic testing method for concrete structures," Cement and Concrete Research. vol.32, no. 11, pp.1763-1769, 2002.

[7] S. Sathiyanarayanan, P. Natarajan, K. Saravanan, S. Srinivasan, and G. Venkatachari, "Corrosion monitoring of steel in concrete by galvanostatic pulse technique," Cement and concrete composites. vol. 28, no. 7, pp.630637, 2006.

[8] M. G. Pujar, N. Parvathavarthini, R. K. Dayal and S. Thirunavukkarasu, "Assessment of intergranular corrosion (IGC) in 316 (N) stainless steel using electrochemical noise (EN) technique," Corrosion Science. vol. 51, no. 8, pp.1707-1713, 2009.

[9] W. Morris, A. Vico, M. Vazquez, and S. R. De Sánchez, "Corrosion of reinforcing steel evaluated by means of concrete resistivity measurements," Corrosion Science. vol. 44, no. 1, pp. 81-99, 2002.

[10] C. Andrade and C. Alonso,"Test methods for on-site corrosion rate measurement of steel reinforcement in concrete by means of the polarization resistance method," Materials and Structures. vol. 37, no. 9, pp. 623-643, 2004.

[11] C. Leung, K. Wan, and L. Chen,"A novel optical fiber sensor for steel corrosion in concrete structures," Sensors. vol.8, no. 3, pp.1960-1976, 2008.

[12] A. Zaki, H. Chai, D. Aggelis, and N. Alver, "Non-destructive evaluation for corrosion monitoring in concrete: A review and capability of acoustic emission technique," Sensors. vol. 15, no. 8, pp.19069-19101, 2015.

[13] S. Akhtar. "Review of nondestructive testing methods for condition monitoring of concrete structures," Journal of construction engineering. 2013.

[14] C. Liu, Q. Bi, and A. E. I. S. Matthews, "EIS comparison on corrosion performance of PVD TiN and $\mathrm{CrN}$ coated mild steel in $0.5 \mathrm{~N} \mathrm{NaCl}$ aqueous solution," Corrosion Science. vol. 43, no. 10, pp.1953-1961, 2001 .

[15] K. Mamun, F. R. Islam, R. N. Deo, A. Chand, A. Cakacaka and K. Prasad, "An Emi Sensor for non-destructive corrosion estimation in concrete." Available online: http://repository.usp.ac.fj/id/eprint/10940 (accessed on 9 March 2019).

[16] d. Alcantara, Naasson, F. d. Silva, M. Guimarães, and M. Pereira, "Corrosion assessment of steel bars used in reinforced concrete structures by means of eddy current testing," Sensors. vol.16, no. 1, p.15, 2016.

[17] K. Perveen, G. E. Bridges, S. Bhadra, and D. J. Thomson, "Corrosion potential sensor for remote monitoring of civil structure based on printed circuit board sensor," IEEE transactions on instrumentation and measurement. vol. 63, no. 10, pp. 2422-2431, 2014.

[18] K. K. Sharma, R. N. Deo, A. Kumar, and K. Mamun, "Rebar corrosion due to chlorides in synergy with sodium, potassium, and magnesium," Construction and Building Materials. vol. 165, pp.533-540, 2018. 